\title{
regras para foulipar, primeiro ano
}

Priscila Borges e Gustavo Laet Gomes

Apresentamos aqui todas as regras de postagens com a \#foulipo que foram proopostas e implementadas semanalmente durante o primeiro ano do projeto no Facebook. ${ }^{1}$ As regras seguiram princípios variados: combinações aleatórias de conteúdo público produzido por usuários Facebook; combinação aleatória de postagens públicas com publicidade; combinação de conteúdo com a intenção de ressignificá-lo sem aleatoriedade; interações em perfis de usuários do Facebook; criação de eventos; combinação de conteúdo interno ao Facebook com conteúdo externo, como vídeos, músicas e imagens; e muitas outras. Acompanha a lista de regras alguns comentários sobre os efeitos gerados e exemplos de postagens que nos chamaram a atenção.

\section{6}

REGRA DA SEMANA DE 27/11 A 3/12

Compartilhe a $10^{a}$ publicação da sua timeline com no mínimo uma hora de intervalo

\footnotetext{
${ }^{1}$ Para saber o que é \#foulipo consulte o manifesto \#foulipo publicado nesta edição de METAgraphias.
} 
METAgraphias: letra F de \#foulipo (criação potencial) v.2 n.3 setembrol2017 regras para foulipar • Priscila Borges e Gustavo Laet Gomes (primborges@gmail.com; guslaet@gmail.com)

entre cada publicação.

(Conta todo tipo de publicação compartilhável, INCLUSIVE propagandas, exceto aquelas sugestões de amizade que não podem ser compartilhadas.)

compartilhamento aleatório dá maior visibilidade às postagens, pois o autor da postagem original recebe uma notificação de que houve compartilhamento, aumentando as chances de mais pessoas verem e curtirem. Além disso, ele estabelece vínculos novos com diferentes perfis, o que reconfigura a organização do feed de notícias.

\section{REGRA DA SEMANA DE 4 A 10/12}

Compartilhe a $7^{a}$ publicação da sua timeline com o texto da $5^{a}$ publicação (adicionando \#foulipo no final), com no mínimo uma hora de intervalo entre cada publicação. Caso a $5^{\text {a }}$ publicação não tenha nenhum texto que possa ser compartilhado, pegue o texto da próxima. Se chegar na $7^{a}$ sem texto, pegue o texto da $7^{a}$ e compartilhe a próxima (e assim por diante até conseguir montar a proposição da regra).

(Conta todo tipo de publicação compartilhável, INCLUSIVE propagandas. Não compartilhe postagens voltadas para público restrito, pois elas só serão visíveis para o público definido originalmente. Se a postagem da regra cair sobre uma dessas, pegue a próxima.)

As composições destas e outras postagens que combinam conteúdos distintos estimulam o leitor a tentar criar um sentido para textos justapostos aleatoriamente. Coincidências inusitadas surpreendem, podendo gerar estranhamento, riso ou raiva.

\section{REGRA DA SEMANA DE 11 A 17/12}

Pegue o primeiro comentário que encontrar que tenha 3 ou mais linhas. Publicar junto com a próxima postagem pública (desde que já não seja um \#foulipo).

(Se, por acaso, ocorrer de você pegar o mesmo comentário de uma postagem anterior, você pode pular para o próximo.)

(Conta todo tipo de publicação compartilhável, INCLUSIVE propagandas. Não compartilhe postagens voltadas para público restrito, pois elas só serão visíveis para o 
METAgraphias: letra F de \#foulipo (criação potencial) v.2 n.3 setembrol2017 regras para foulipar • Priscila Borges e Gustavo Laet Gomes (primborges@gmail.com; guslaet@gmail.com)

público definido originalmente. Se a postagem da regra cair sobre uma dessas, pegue a próxima.)

\section{REGRA DA SEMANA DE 18 A 24/12}

(1) Entre na sua seção de Amigos (clique no seu perfil e em seguida na opção "Amigos").

(2) Clique em "Novas Publicações".

(3) Procure pelo $3^{\circ}$ amigo ou amiga que tenha um número de "novas publicações" correspondente ao dia da semana: domingo $=1$, segunda $=2$ e assim por diante.

(4) Entre no perfil dele ou dela e copie o primeiro texto que você encontrar.

(5) Volte para a sua timeline e compartilhe a primeira propaganda que você encontrar (e que você ainda não tenha compartilhado esta semana) com o texto do post do seu amigo ou amiga que você copiou no passo 4.

(Se, por acaso, ocorrer de você pegar o mesmo comentário de uma postagem anterior, você pode pular para o próximo.)

Novamente a regra de combinar conteúdos aleatórios, mas desta vez enfatizando justamente as postagens publicitárias introduzidas pelo próprio Facebook. $\mathrm{O}$ compartilhamento de conteúdo publicitário não é uma prática do usuário normal do Facebook, o que causa estranhamento e faz com que a publicidade seja percebida fora do seu contexto ideal, onde ela se camufla com outros conteúdos.

\section{REGRA DA SEMANA DE 25 A $31 / 12$}

(0) [Opcional] Defina sua timeline para as histórias mais recentes. (Clique nas reticências (...) ao lado do link "Feed de Notícias" logo abaixo do seu nome no canto superior esquerdo da página principal do Facebook.)

(1) Copie o primeiro texto que você encontrar na sua timeline com 4 ou mais linhas (pode ser postagem ou comentário, mas ignore postagens com a \#foulipo).

(2) Entre na sua seção de Amigos (clique no seu perfil e em seguida na opção "Amigos"). 
(3) Clique em "Novas Publicações".

(4) Procure pelo $3^{\circ}$ amigo ou amiga que tenha um número de "novas publicações" correspondente ao dia da semana: domingo $=1$, segunda $=2$ e assim por diante.

(5) Entre no perfil dele ou dela e compartilhe a primeira postagem pública que você encontrar com o texto que você tinha copiado no passo 1.

A possibilidade de alterar o modo como são mostradas as postagens no Feed de Notícias chama atenção para o fato de que o feed é construído pelo Facebook e, portanto, não é neutro.

\section{7}

\section{REGRA DA SEMANA DE 1 A 7/1}

(0) [Opcional] Defina sua timeline para as histórias mais recentes. (Clique nas reticências (...) ao lado do link "Feed de Notícias" logo abaixo do seu nome no canto superior esquerdo da página principal do Facebook.)

(1) Copie o primeiro texto que você encontrar na sua timeline que faça sentido (isto é, que não seja interjeição, figurinhas ou links).

(2) Pule cinco postagens.

(3) Procure a primeira postagem pública que possa ilustrar o texto que você copiou no passo $1 \mathrm{com}$ qualquer elo de sentido. Quanto mais distante do sentido original melhor, mas fica a seu critério. Compartilhe esta postagem com o texto do passo 1 e a \#foulipo.

Esta é a primeira regra em que os participantes são instados a introduzir elementos de sentido adicional a um procedimento que tem elementos de aleatoriedade.

\section{REGRA DA SEMANA DE 8 A 14/1}

(0) [Opcional] Defina de vez em quando sua timeline para as histórias mais recentes. (Clique nas reticências (...) ao lado do link "Feed de Notícias" logo abaixo do seu nome no canto superior esquerdo da página principal do Facebook.)

(1) Compartilhe um anúncio patrocinado com a \#foulipo. 
(2) Procure um texto na sua timeline, de publicação ou comentário, que possa ter alguma relação semântica com o anúncio do passo 1 (ela não precisa ser óbvia). Copie este texto e cole como comentário na sua postagem do passo $1 \mathrm{com}$ a \#foulipo.

(3) Procure um segundo texto na sua timeline que forme relação semântica com o anúncio do passo 1 e que não seja da mesma postagem do passo 2. Copie este texto e cole como comentário na sua postagem do passo $1 \mathrm{com}$ a \#foulipo.

Nesta regra tentamos explorar os comentários. No entanto, logo percebemos que conteúdo dos comentários tem pouca influência na construção da timeline. Comentários parecem contar apenas quantitativamente.

\section{REGRA DA SEMANA DE 15 A 21/1}

(1) Copie o nome de uma das pessoas que aparecem na coluna direita da sua timeline na seção "Pessoas que você talvez conheça". (Se não aparecer esta seção (que só surge de vez em quando), você pode clicar no ícone onde aparecem as solicitações de amizade que lá tem várias sugestões.)

(2) Procure o nome que você copiou no passo 1 no Google.

(3) Clique em "Notícias" para mostrar notícias relacionadas com a sua busca.

(4) Escolha uma notícia (por qualquer critério), clique nela e copie o link (tem que clicar, do contrário o resultado será uma página do Google).

(5) Compartilhe esta notícia na sua timeline com a \#foulipo.

(6) [Opcional] Copie um trecho aleatório da notícia do passo 4 ou ainda um comentário sobre a notícia (quando houver) e cole como texto da postagem passo 5, entre aspas.

Esta é a primeira regra em que os participantes devem buscar conteúdo fora do Facebook. Ela sugere inicialmente uma espécie de investigação sobre uma pessoa desconhecida oferecida pelo Facebook como amigo potencial. Naturalmente a "investigação" não gera nenhum resultado coerente, dado que o Google não fornece na grande maioria das vezes resultados relativos àquela pessoa específica pela qual se procura. Nomes são por demais genéricos para servir de identidade virtual. 
METAgraphias: letra F de \#foulipo (criação potencial) v.2 n.3 setembrol2017

regras para foulipar • Priscila Borges e Gustavo Laet Gomes (primborges@gmail.com; guslaet@gmail.com)

\section{REGRA DA SEMANA DE 22 A 28/1}

(1) Copie o nome de uma das pessoas que aparecem na coluna direita da sua timeline na seção "Pessoas que você talvez conheça". (Se não aparecer esta seção (que só surge de vez em quando), você pode clicar no ícone onde aparecem as solicitações de amizade que lá tem várias sugestões.)

(2) Procure o nome que você copiou no passo 1 no Google.

(3) Clique em "Vídeos" para mostrar vídeos relacionadas com a sua busca.

(4) Escolha um vídeo (por qualquer critério), clique nele e copie o link (tem que clicar, do contrário o resultado será uma página do Google).

(5) Compartilhe este vídeo na sua timeline com a \#foulipo.

(6) [Opcional] Copie um comentário feito sobre o vídeo na página original (passo 4) e cole como texto da postagem passo 5.

Ainda no espírito de investigação sobre potenciais amigos, os participantes devem agora procurar por vídeos. Novamente os resultados não guardam relação com os nomes sugeridos pelo Facebook, mas do ponto de vista da recepção percebemos que vídeo têm impacto muito maior do que postagens estáticas.

\section{REGRA DA QUINZENA DE 29/1 A 11/2}

(1) Escolha uma notícia de política na sua timeline.

(2) Selecione duas ou três palavras da notícia (no título, na chamada ou no texto; podem ser ainda palavras-chave).

(3) Procure essas palavras no google, acrescentando na busca a expressão "+letra" (se for uma notícia em outra língua traduza o termo letra para a língua adequada, por exemplo, "+lyrics" em inglês).

(4) Escolha, entre os resultados, uma música para ilustrar a sua notícia.

(5) Compartilhe a notícia na sua timeline com pelo menos 4 versos da música selecionada, mais a \#foulipo. 
Usuários do Facebook são particularmente sensíveis a citações de celebridades pop. A vinculação de conteúdo musical a notícias sobre política tem impacto interessante. As notícias, em geral, são apresentadas com uma foto que fisca o usuário e a música costuma provocar reações.

REGRA DA SEMANA DE 19 A 25/02

(0) [Opcional] Defina de vez em quando sua timeline para as histórias mais recentes. (Clique nas reticências (...) ao lado do link "Feed de Notícias" logo abaixo do seu nome no canto superior esquerdo da página principal do Facebook.)

(1) Compartilhe a $6^{a}$ publicação pública da sua timeline com o texto da $4^{a}$ publicação (adicionando \#foulipo no final). Caso a $4^{a}$ publicação não tenha nenhum texto que possa ser compartilhado, pegue o texto da próxima. Se chegar na $6^{\text {a }}$ sem texto, pegue o texto da $6^{\text {a }}$ e compartilhe a próxima (e assim por diante até conseguir montar a proposição da regra).

REGRA DA SEMANA DE 26/2 A 4/3

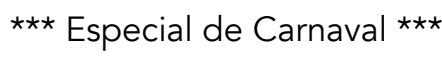

Compartilhe qualquer postagem pública da sua timeline incluindo como texto alguma marchinha de carnaval e a \#foulipo.

\section{REGRA DA SEMANA DE 5 A 11/03}

(1) Entre no site trends24.in (que mostra os trending topics mundiais do twitter, isto é, as hashtags mais utilizadas).

(2) Copie a hashtag que é o trending topic atual.

(3) Procure por esta hashtag no Facebook (cole no campo de busca).

(4) Compartilhe qualquer postagem entre resultados acrescentando a \#foulipo.

Nesta regra introduzimos pela primeira vez um elemento do Twitter, buscando produzir postagens que tenham relação com o assunto mais falado do momento, o que tem o potencial de produzir maior interação por parte de usuários não participantes. 
METAgraphias: letra F de \#foulipo (criação potencial) v.2 n.3 setembrol2017

regras para foulipar • Priscila Borges e Gustavo Laet Gomes (primborges@gmail.com; guslaet@gmail.com)

\section{REGRA DA SEMANA DE 12 A $18 / 03$}

(0) [Opcional] Defina de vez em quando sua timeline para as histórias mais recentes. (Clique nas reticências (...) ao lado do link "Feed de Notícias" logo abaixo do seu nome no canto superior esquerdo da página principal do Facebook.)

(1) Copie o primeiro texto original significativo que você encontrar na sua timeline, isto é, o primeiro texto que algum dos seus amigos escreveu e não um compartilhamento de terceiros, texto de propagandas ou citação de notícias, mas pode ser uma citação que ele escreveu por conta própria. Este texto não precisa ser de uma postagem pública, já que não há restrição para cópia de textos não públicos.

(2) Compartilhe a primeira publicação original pública (muito importante) que você encontrar depois da postagem do passo 1 com o texto copiado no passo 1. Novamente, escolha apenas publicações com textos significativos, fotos ou outros conteúdos produzidos pelo autor da postagem.

Nesta regra propomos restringir as postagens a conteúdo autoral, evitando republicações.

\section{REGRA DA SEMANA DE 19 A 25/03}

(1) Escolha um parágrafo aleatório de um livro que você está lendo. (Se não estiver lendo nenhum, pegue um livro qualquer da sua estante ou um PDF, para facilitar o Ctrl+C, Ctrl+V.)

(2) Publique o parágrafo escolhido na sua timeline sem aspas e sem indicar a origem e com a hashtag \#foulipo.

(3) [Opcional] Você pode acrescentar um daqueles "humores" ("sentindo-se ...") do Facebook, também de modo aleatório.

Introduzimos agora citações de livros, também muito populares. No entanto, diferentemente do que ocorre normalmente, as citações publicadas não refletem estados de ânimo dos participantes nem mensagens ou afirmações.

\section{REGRA DA SEMANA DE 26/03 A 01/04}

(0) [Opcional] Defina de vez em quando sua timeline para as histórias mais recentes. (Clique nas reticências (...) ao lado do link "Feed de Notícias" logo abaixo do seu nome 
METAgraphias: letra F de \#foulipo (criação potencial) v.2 n.3 setembrol2017 regras para foulipar • Priscila Borges e Gustavo Laet Gomes (primborges@gmail.com; guslaet@gmail.com)

no canto superior esquerdo da página principal do Facebook.)

(1) Copie o primeiro texto de postagem da sua timeline com pelo menos duas linhas e cole no espaço de criação de nova postagem.

(2) Selecione 5 palavras com 4 letras ou mais e apague o resto.

(3) Organize-as na forma de uma aldravia - um poema de seis linhas em que cada linha contém apenas uma palavra. A nossa aldravia, porém, só terá 5 linhas porque o Facebook corta a postagem a partir da sexta linha. Você pode manter a ordem em que elas apareciam no texto original ou mudar a ordem para que o poema faça mais sentido. Mas uma vez iniciado o processo publique alguma coisa, por mais nonsense que fique.

(4) Coloque a \#foulipo ao lado da quinta palavra (para ela não sair cortada).

(5) Escolha um daqueles "humores" ou "atividades" do Facebook que tenha alguma relação de sentido com o seu poema.

Esta regra foi provavelmente a que mais se aproximou de uma produção ao estilo oulipo. Ela teve também bastante sucesso, gerando uma quantidade grande de novos participantes. Veja um exemplo abaixo:

\begin{tabular}{|c|c|c|}
\hline \multicolumn{3}{|c|}{$\begin{array}{l}\text { repassando } \\
\text { para } \\
\text { refletir } \\
\text { copie } \\
\text { cole \#foullipo }\end{array}$} \\
\hline \multicolumn{3}{|c|}{ 23 55 people reached } \\
\hline 凸 Like & re $\square$ Comment $\Rightarrow$ Share & in \\
\hline
\end{tabular}


METAgraphias: letra F de \#foulipo (criação potencial) v.2 n.3 setembrol2017 regras para foulipar • Priscila Borges e Gustavo Laet Gomes (primborges@gmail.com; guslaet@gmail.com)

\section{REGRA DA SEMANA DE 02 A 08/04}

(1) Entre na sua seção de Amigos (clique no seu perfil e em seguida na opção "Amigos").

(2) Clique em "Novas Publicações".

(3) Procure pelo $2^{\circ}$ amigo ou amiga que tenha um número de "novas publicações" correspondente ao dia da semana: domingo $=1$, segunda $=2$ e assim por diante. (Se a pessoa encontrada no passo 3 não permitir publicações em seu mural ou se cair em uma pessoa em cuja página você já publicou esta semana, volte ao passo 3 e procure a próxima pessoa com "novas publicações" correspondentes ao dia da semana.)

(4) Entre no perfil da pessoa encontrada no passo 3 e escreva no mural dele ou dela um ditado, provérbio ou trecho de cantiga popular alterando uma única palavra do dito por outra que tenha a mesma sonoridade. Altere, por exemplo, "gato" por "jato", "calo" por "falo" etc. Não se esqueça de acrescentar no final a \#foulipo. Não repita ditados.

(5) [Opcional] Escolha a opção "sentindo-se engraçado" (ou feeling funny).

Esta regra demandava que os participantes produzissem trocadilhos a partir de ditados populares. Dois exemplos interessantes:

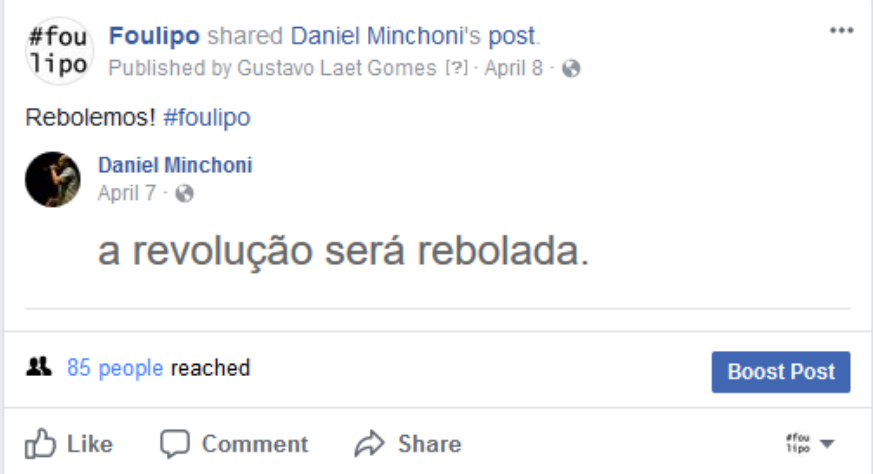


METAgraphias: letra F de \#foulipo (criação potencial) v.2 n.3 setembrol2017 regras para foulipar • Priscila Borges e Gustavo Laet Gomes (primborges@gmail.com; guslaet@gmail.com)

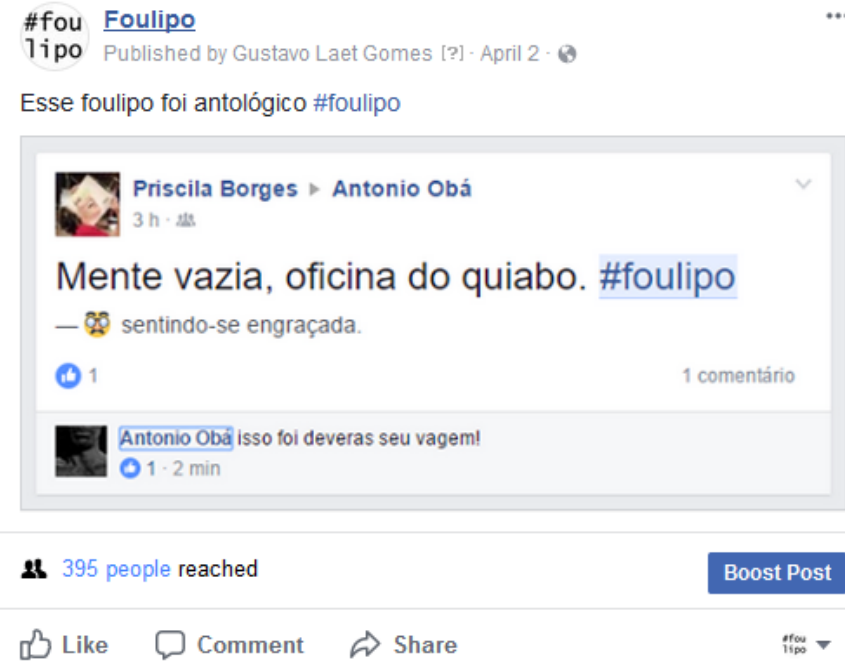

\section{REGRA DA SEMANA DE 09 A 15/04}

(1) Encontre uma postagem na sua timeline que tenha pelo menos dois emojis (aquelas figurinhas). Copie o texto desta postagem (incluindo os emojis). Você pode pegar também o texto de um comentário (se os emojis estiverem muito escassos na sua timeline).

(2) Cole o texto do passo 1 numa nova postagem e substitua os emojis da mensagem original por uma descrição deles. Quanto mais completa, melhor. Por exemplo, "carinhha amarela sorridente com uma auréola azul sobre a cabeça", ou ainda "coração vermelhor". Dica: coloque a sua descrição entre <> para ficar destacada do texto principal.

(3) Não se esqueça de acrescentar a \#foulipo.

Nesta regra o participante deveria remover os elementos gráficos (emojis) das postagens, enfatizando o caráter textual da timeline. Os emojis, reduzidos a uma mera descrição, acabavam esvaziados de sentido. A proposição da regra gerou o desafio abaixo: 
METAgraphias: letra F de \#foulipo (criação potencial) v.2 n.3 setembrol2017 regras para foulipar • Priscila Borges e Gustavo Laet Gomes (primborges@gmail.com; guslaet@gmail.com)

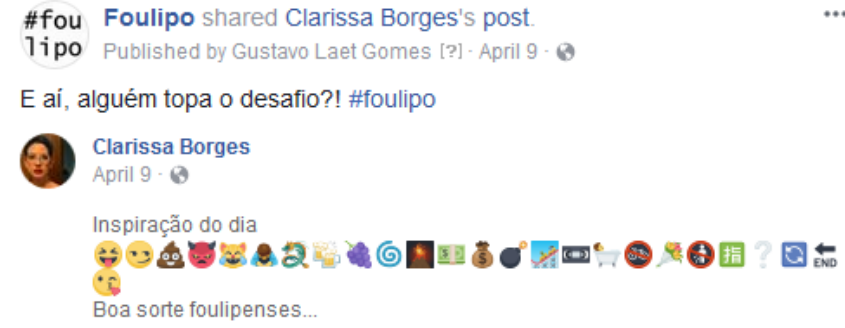

\section{... que foi traduzido assim:}

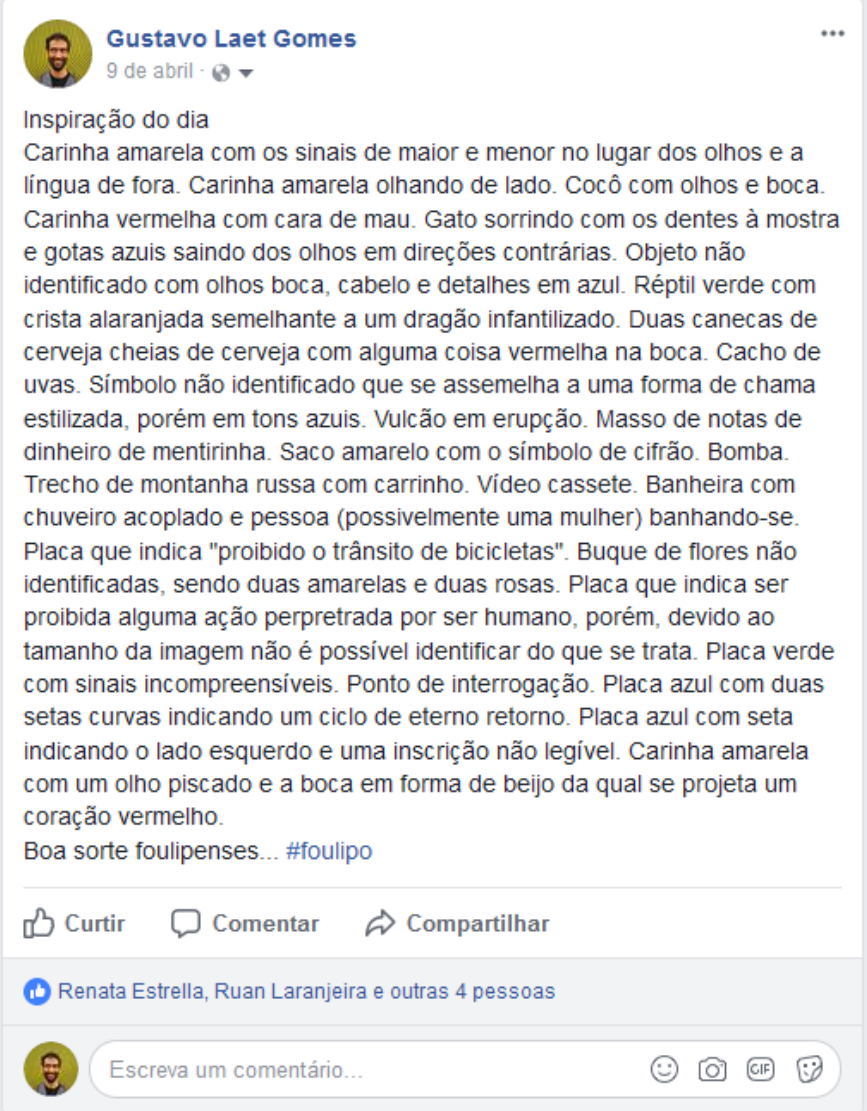

\section{REGRA DA SEMANA DE 16 A 22/04}

(1) Escolha um texto de propaganda da sua timeline que esteja anunciando um 
produto, ou seja, um texto focado na venda de alguma coisa. Copie esse texto. (Não repita textos.)

(2) Procure uma imagem bonita e pública na sua timeline. Pode ser foto, vídeo, notícia. O ponto é que a imagem tem que ser interessante, agradável, instigante e, como tal, vendável. (Não repita imagens.)

(3) Compartilhe a postagem da imagem do passo $2 \mathrm{com}$ o texto do passo 1. Não se esqueça da \#foulipo.

(4) Marque quatro amigos pela seguinte regra: some o dia do mês com a hora em que você está postando (tipo $16+14$ ) e encontre a letra correspondente (sendo que $A=1$, $B=2$ etc., não se esqueça de incluir $K, W$ e Y). Na hora de marcar os amigos, digite a letra resultante (no caso do exemplo $16+14=30-26=4$, portanto $D$ ), e marque os quatro primeiros que o facebook sugerir, mas pule aqueles que você já marcou em postagens anteriores.

Nesta regra, "amigos" são "cutucados" ao terem seu nome vinculado à postagem, como se elas fossem de seu interesse.

\section{REGRA DA SEMANA DE 23 A 29/04}

(1) Encontre uma postagem autoral (ou seja, escrita por seu amigo e não uma republicação) de cunho político da sua timeline. Copie o texto. (Se a postagem for muito longa, você pode copiar um trecho significativo você julgue que o autor possa reconhecer caso ele venha a ler a postagem na sua timeline.)

(2) Cole o texto em uma nova postagem e substitua todos os adjetivos* por "<adjetivo>" (sem as aspas, mas com os sinais <>). Não se esqueça de acrescentar a \#foulipo.

* Sobre o que deve ser considerado adjetivo, ver dicas nos comentários.

Os discursos inflamados da polarização políticas são esvaziados de seus adjetivos intensificadores, dando ênfase à forma.

\section{REGRA DA SEMANA DE 30/4 A 6/5}

(1) Escolha uma música que você goste. Procure um áudio ou vídeo dela que toque no 
METAgraphias: letra F de \#foulipo (criação potencial) v.2 n.3 setembrol2017 regras para foulipar•Priscila Borges e Gustavo Laet Gomes (primborges@gmail.com; guslaet@gmail.com)

Facebook (no YouTube, por exemplo) e anote o link em algum lugar. Você vai precisar dele várias vezes esta semana.

(2) Crie uma nova postagem toda vez, com o link que você anotou no passo 1 e, como texto, coloque o primeiro verso da música. Na próxima postagem você deverá colocar o segundo verso, depois o terceiro e assim por diante, até a música terminar. (Acrescente no fim do verso - e no início se não for o primeiro - reticências (...) para indicar que a música continua.) Não se esqueça de acrescentar a \#foulipo.

Você deve postar, a cada vez, um verso da música. Pode ser várias vezes no dia. Quando a música acabar, você pode começar de novo, ou então escolher uma outra e fazer a mesma coisa, todos os dias, até o fim da semana.

Esta regra ocorreu na mesma semana em que morreu o cantor Belchior.

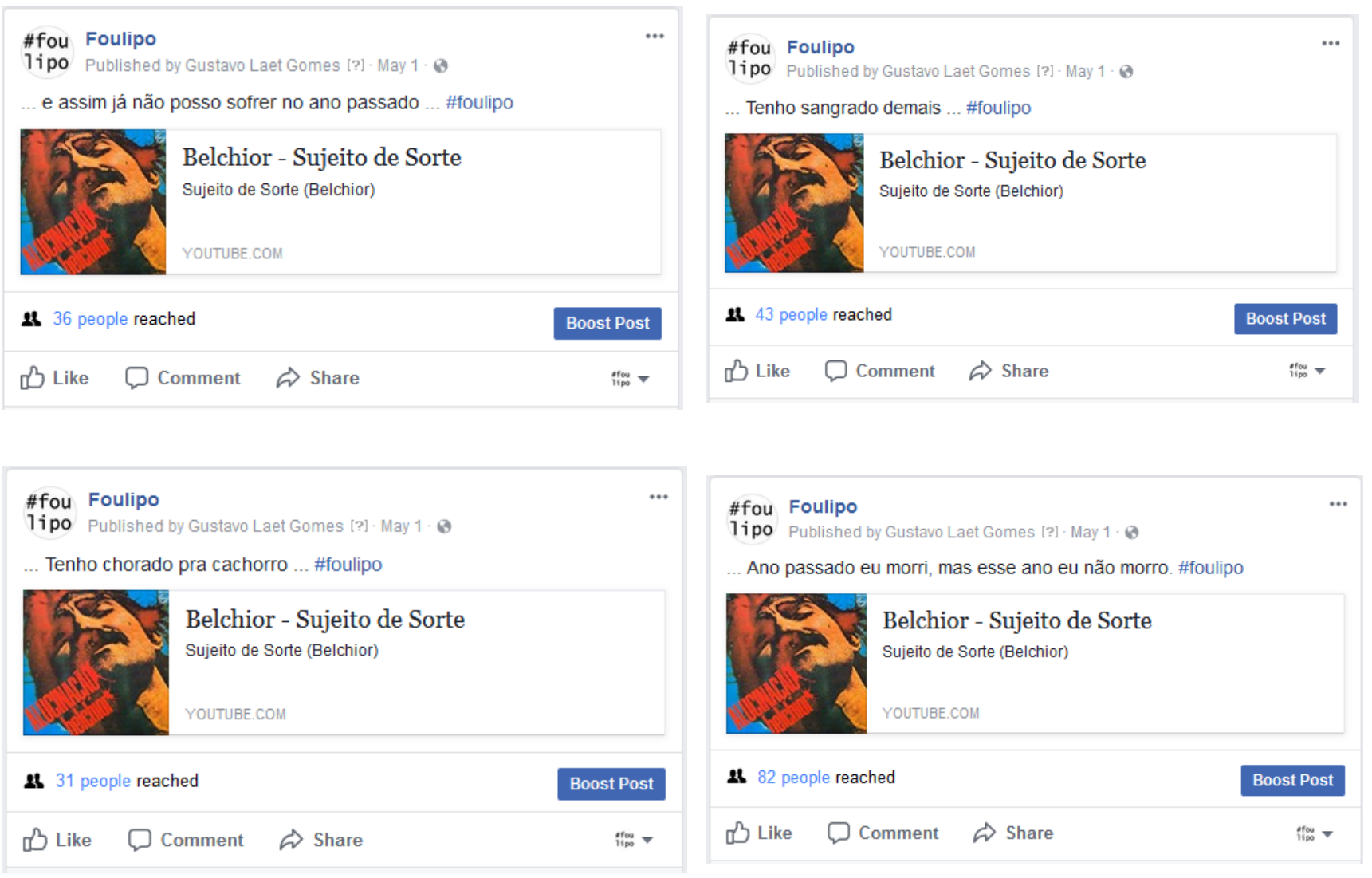

\section{REGRA DA SEMANA DE 7 A 13/5}

(0) [Opcional] Defina de vez em quando sua timeline para as histórias mais recentes. 
METAgraphias: letra F de \#foulipo (criação potencial) v.2 n.3 setembrol2017 regras para foulipar • Priscila Borges e Gustavo Laet Gomes (primborges@gmail.com; guslaet@gmail.com)

(Clique nas reticências (...) ao lado do link "Feed de Notícias" logo abaixo do seu nome no canto superior esquerdo da página principal do Facebook.)

(1) Copie o texto da quinta postagem que aparecer na sua timeline. (Se não houver texto, pegue o texto de algum comentário da quinta postagem ou então o texto da próxima postagem depois da quinta que tenha.)

(2) Compartilhe o primeiro meme que você encontrar depois do passo 1 com o texto do passo 1. Não se esqueça de acrescentar a \#foulipo.

\section{REGRA DA SEMANA DE 14 A 20/5}

(1) Copie o segundo texto com duas ou mais linhas que você encontrar na sua timeline (vale postagem ou comentário).

(2) Procure uma foto de algum legume ou verdura. Pode ser em qualquer lugar: Google, Facebook, Twitter, Instagram, Pinterest etc.

(3) Compartilhe a foto que você escolheu no passo 2 com o texto do passo 1 . Não se esqueça de acrescentar a \#foulipo. 
METAgraphias: letra F de \#foulipo (criação potencial) v.2 n.3 setembrol2017 regras para foulipar • Priscila Borges e Gustavo Laet Gomes (primborges@gmail.com; guslaet@gmail.com)

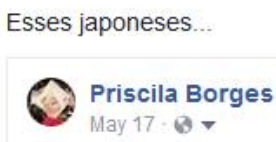

Os japoneses têm hábitos admiráveis que todos poderiamos adaptar em nossos dias. Certamente seria uma mudança muito significativa na vida de todos nós! \#foulipo

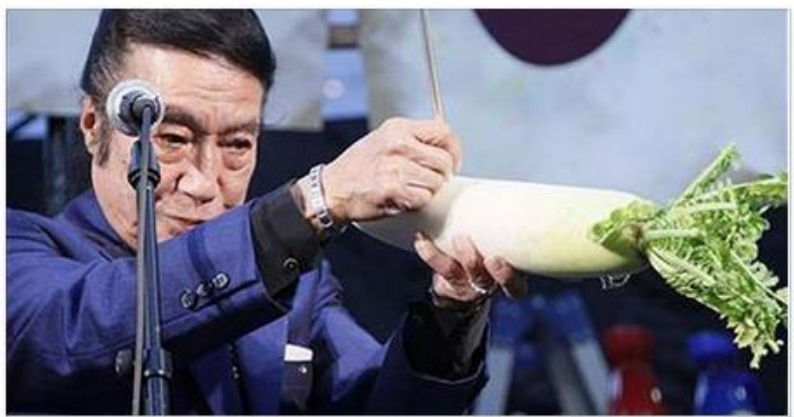

Image: G1 > Planeta Bizarro - NOTÍCIAS - Músico japonês toca flauta feita ... Found on Google from g1.globo.com IMAGES.GOOGLE,COM

24. 97 people reached

It Like $\square$ Comment $\Rightarrow$ Share $i_{t \infty}^{+\infty}-$

\section{REGRA DA SEMANA DE 21 A 27/5}

(1) Escolha uma frase recente de um político contemporâneo, extraída de notícias da imprensa.

(2) Cole-a numa nova postagem do Facebook, entre aspas, e indique, como autor (da frase), algum escritor, poeta, estadista etc., enfim, alguma pessoa das que costumam ter suas frases citadas na internet. De preferência alguém que já morreu. Não se esqueça de acrescentar a \#foulipo. 
METAgraphias: letra F de \#foulipo (criação potencial) v.2 n.3 setembrol2017 regras para foulipar • Priscila Borges e Gustavo Laet Gomes (primborges@gmail.com; guslaet@gmail.com)

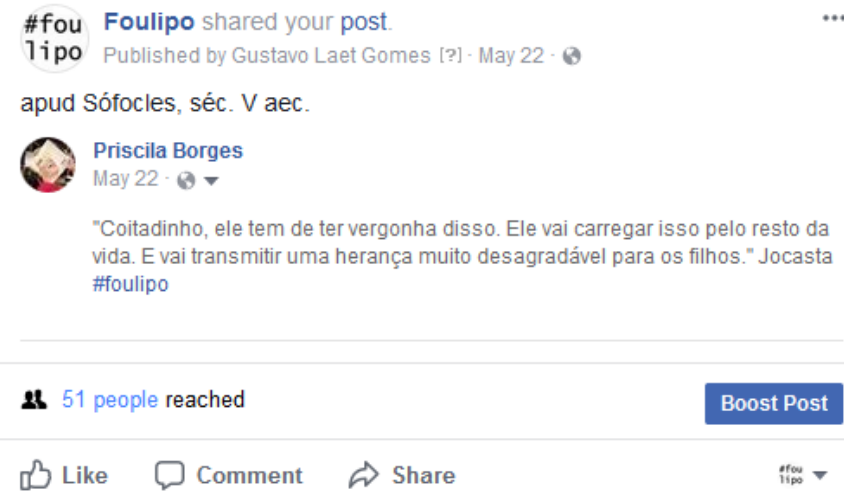

\section{REGRA DA SEMANA DE 28/5 A $3 / 6$}

(1) Copie o primeiro texto da sua timeline com fundo colorido. (Se você não encontrar textos com fundo colorido, pegue a primeira postagem que contenha somente texto.)

(2) Acesse o Google Translate (https://translate.google.com/) e cole o texto que você copiou no passo 1 no bloco do texto a esquerda.

(3) Certifique-se de que o Google Translate detectou corretamente a língua da postagem que você copiou. Caso contrário, selecione a língua correta.

(4) Selecione uma língua para tradução na caixa da esquerda segundo a seguinte regra: some o dia do mês com a hora em que você está postando (tipo $16+14$ ) e encontre a letra correspondente (sendo que $A=1, B=2$ etc., não se esqueça de incluir $K, W$ e $Y$ ). Clique na caixa de seleção (triângulo voltado para baixo) ao lado das línguas e selecione uma língua que comece com a letra resultante (no caso do exemplo $16+14=30$ - 26 $=4$, portanto $D$ - Dinamarquês, por exemplo).

(5) Copie a tradução e cole numa nova postagem do Facebook. Se você a copiou de uma postagem com fundo colorido, coloque o mesmo fundo na sua postagem. Não se esqueça da \#foulipo.

Nesta regra utilizamos o Google Translate para traduzir conteúdos do Facebook para línguas aleatórias invertendo a funcionalidade do Facebook que traduz conteúdos de outras línguas para a língua do usuário. 
METAgraphias: letra F de \#foulipo (criação potencial) v.2 n.3 setembrol2017

regras para foulipar • Priscila Borges e Gustavo Laet Gomes (primborges@gmail.com; guslaet@gmail.com)

\section{REGRA DA SEMANA DE 4 A 10/6}

(1) Copie o texto de uma postagem qualquer da sua timeline que tenha pelo menos 19 palavras.

(2) Cole numa nova postagem e colete 5 palavras da seguinte forma: deixe a $1^{\mathrm{a}}$ palavra, apague 2 palavras; deixe a $2^{\text {a }}$ palavra, apague 3 palavras; deixe a $3^{a}$ palavra, apague 4 palavras; deixe a $4^{\mathrm{a}}$ palavra, apague 5 palavras; deixe a $5^{\mathrm{a}}$ palavra, apague o restante. Ignore os artigos (isto é, quando sair artigo, pegue a próxima palavra), pois eles atrapalham. Você também pode ignorar preposições se quiser.

(3) Organize as 5 palavras restantes da maneira que você quiser, uma palavra por linha. Na quinta linha acrescente a \#foulipo.

Novo poema aleatório de 5 palavras.

\section{REGRA DA SEMANA DE 11 A 17/6}

(1) Copie o texto da primeira postagem que não seja propaganda e que tenha texto da sua timeline.

(2) Compartilhe a primeira postagem pública que não seja propaganda depois da postagem do passo $1 \mathrm{com}$ o texto da primeira. Não se esqueça de acrescentar a \#foulipo.

\section{REGRA DA SEMANA DE 18 A 24/6}

(1) Comece uma nova postagem com a seguinte frase: "VOCÊ SABIA..." (assim em caixa alta e sem as aspas).

(2) Pule para a linha seguinte e escreva um spoiler, isto é, conte o final ou alguma coisa surpreendente de uma história qualquer, pode ser de literatura, filme, conto de fadas, folclore, novela, série, enfim, qualquer. Pode ser história antiga ou recente, não importa. Termine seu spoiler com uma interrogação, para funcionar com o VOCÊ SABIA do passo 1.

(3) Ao final, acrescente a \#foulipo.

Nesta regra jogamos com a neura em torno da revelação de spoilers. 
METAgraphias: letra F de \#foulipo (criação potencial) v.2 n.3 setembrol2017 regras para foulipar • Priscila Borges e Gustavo Laet Gomes (primborges@gmail.com; guslaet@gmail.com)

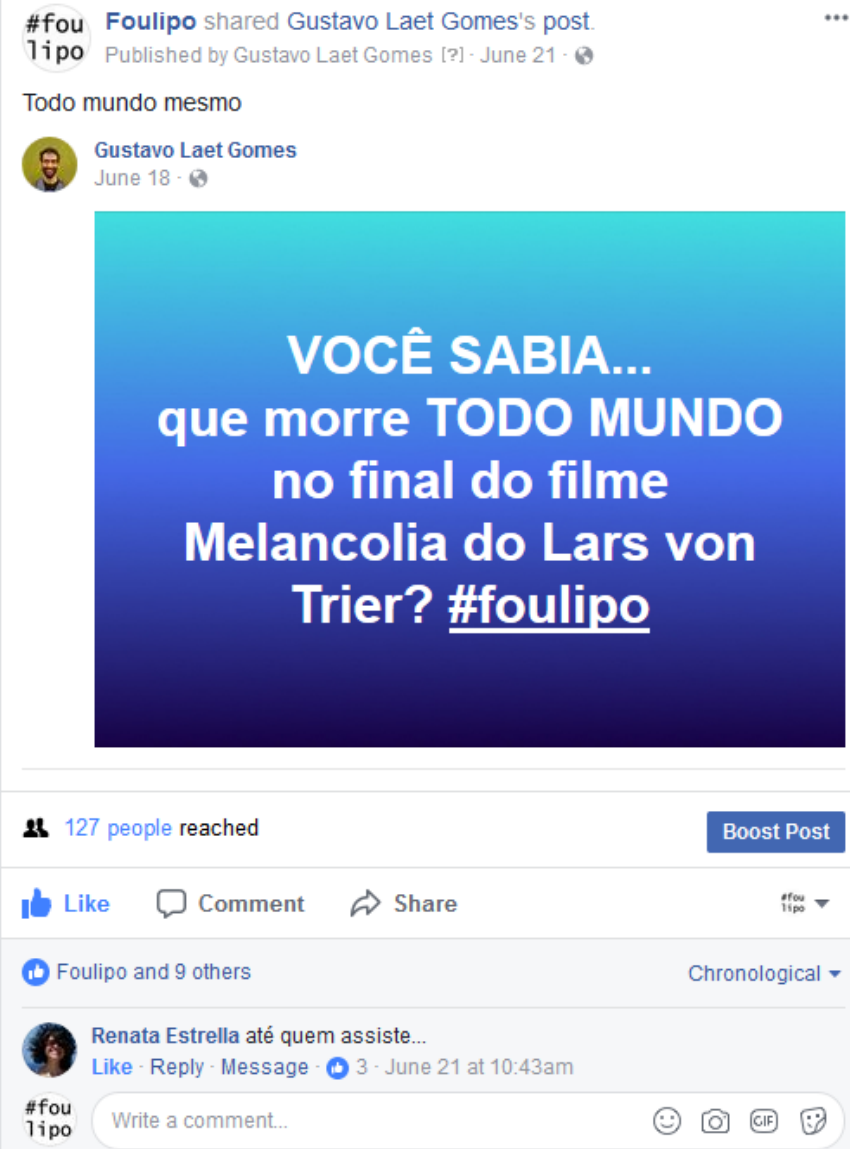


METAgraphias: letra F de \#foulipo (criação potencial) v.2 n.3 setembrol2017 regras para foulipar • Priscila Borges e Gustavo Laet Gomes (primborges@gmail.com; guslaet@gmail.com)

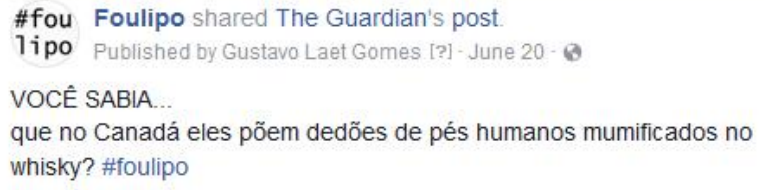

For more than 40 years the Downtown hotel in Dawson City has served up the sourtoe cocktail - now someone's stolen the toe.

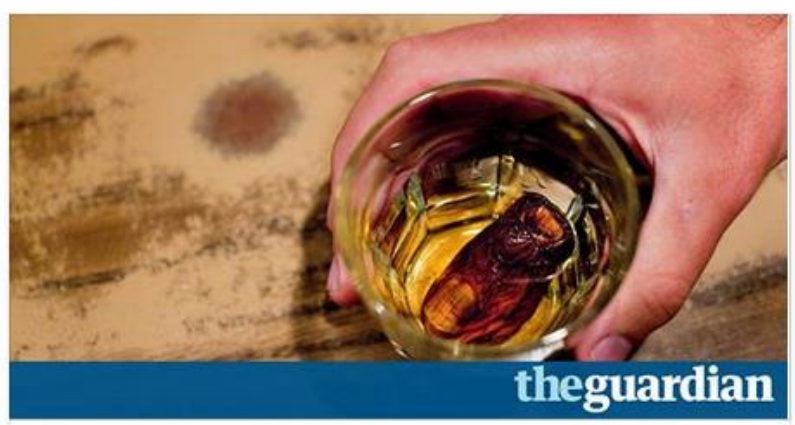

Canada police investigate theft of mummified human toe served in drinks

Yukon bar's 40-year-old signature drink, the sourtoe cocktail, featured the blackened toe inside - until a customer allegedly ran off with it

THEGUARDIAN.COM

21 129 people reached

1 Like $\square$ comment $\Rightarrow$ Share

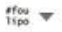


METAgraphias: letra F de \#foulipo (criação potencial) v.2 n.3 setembrol2017 regras para foulipar • Priscila Borges e Gustavo Laet Gomes (primborges@gmail.com; guslaet@gmail.com)

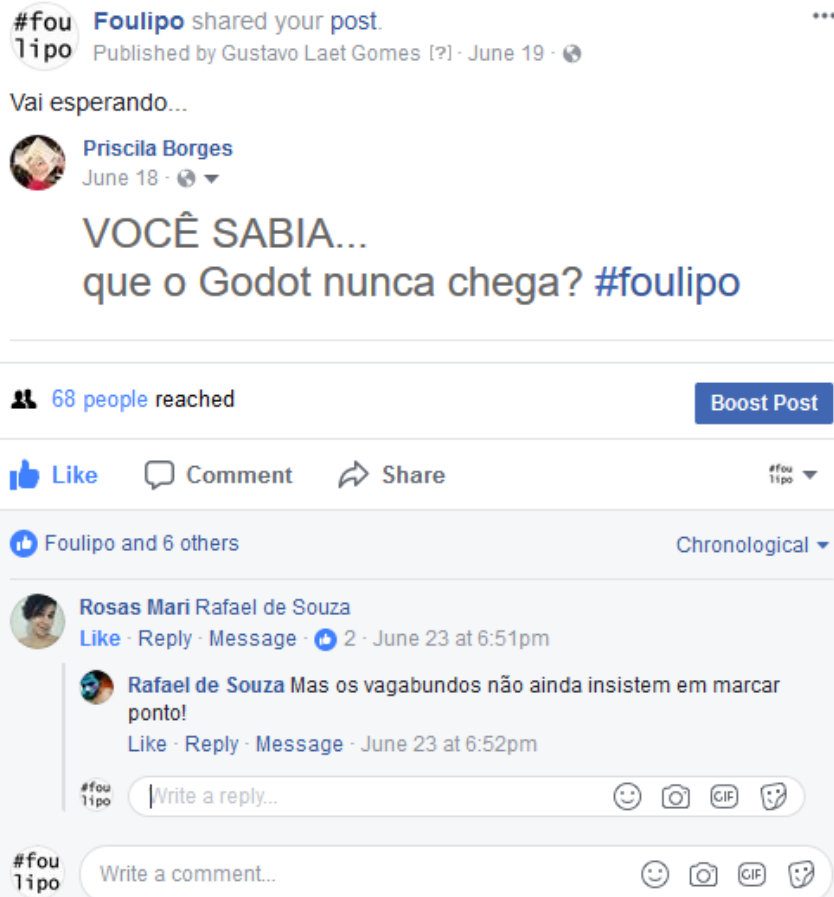

\section{REGRA DA SEMANA DE 25/06 A 1/7}

(1) Entre no site de horóscopo online de sua preferência.

(2) A partir do signo equivalente à hora atual (por exemplo, à 1 AM ou PM; Áries, às 2, Touro; e assim por diante), conte o número equivalente da unidade dos minutos. Por exemplo: Se agora são 5:58, você parte do Leão e conta 8, caindo portanto em Áries (pois quando chega no fim você deve voltar para o começo). Esse será o seu signo.

(3) Agora conte a dezena dos minutos e pegue a mensagem. No caso do exemplo acima, você deve copiar o texto de Virgem.

(4) Crie uma nova postagem no Facebook e escreva: "Horóscopo de Hoje". Pule uma linha e escreva o signo em caixa alta (no exemplo, "LEÃO"). Pule outra linha e cole a mensagem de Virgem que você copiou no passo 3. Ao final, acrescente a \#foulipo.

Nesta regra propomos a criação de horóscopos aleatórios. Houve, porém, quem decidisse propor seu próprio horóscopo: 


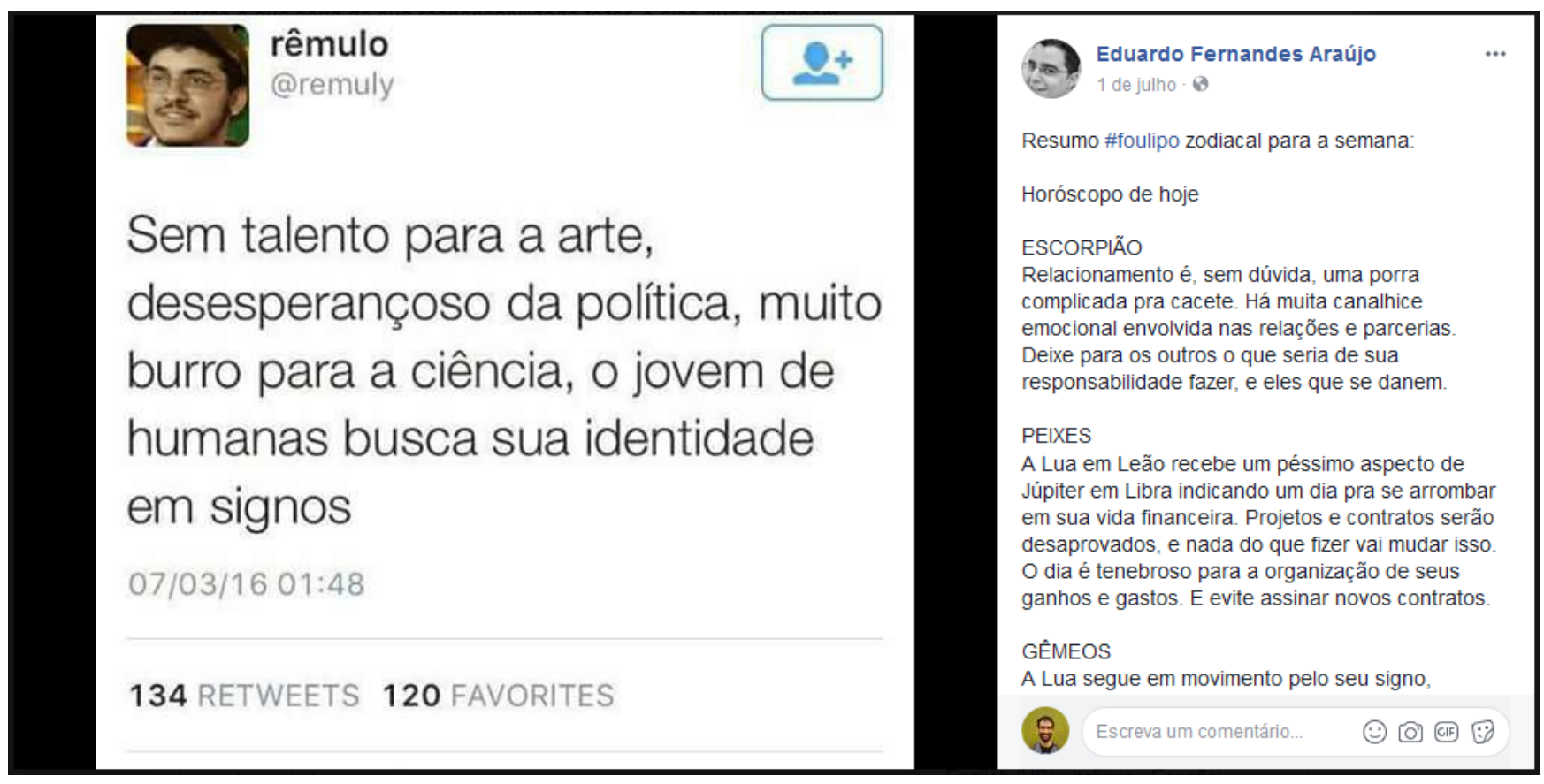

Texto completo abaixo:

Resumo \#foulipo zodiacal para a semana:

Horóscopo de hoje

\section{ESCORPIÃO}

Relacionamento é, sem dúvida, uma porra complicada pra cacete. Há muita canalhice emocional envolvida nas relações e parcerias. Deixe para os outros o que seria de sua responsabilidade fazer, e eles que se danem.

\section{PEIXES}

A Lua em Leão recebe um péssimo aspecto de Júpiter em Libra indicando um dia pra se arrombar em sua vida financeira. Projetos e contratos serão desaprovados, e nada do que fizer vai mudar isso. O dia é tenebroso para a organização de seus ganhos e gastos. E evite assinar novos contratos.

\section{GÊMEOS}

A Lua segue em movimento pelo seu signo, trolando tretas desafiadoras com Vênus. Você vai ter uma dificuldade ducaralho pra demonstrar os seus sentimentos nas relações. Se escolher agir de acordo com seu coração, é certo que só vai se lascar.

\section{CÂNCER}

Hoje o universo conspira contra você e seu poder de comunicação não está com nada. Péssima a hora para investir num curso, viagem ou aprimoramento. Evite falar sobre seus sentimentos. Melhor mesmo nem se levantar da cama. 
METAgraphias: letra F de \#foulipo (criação potencial) v.2 n.3 setembrol2017

regras para foulipar • Priscila Borges e Gustavo Laet Gomes (primborges@gmail.com; guslaet@gmail.com)

LEÃO

Sua desconfiança acentuada é insuportável, conforme memórias e segredos são remexidos. Pague logo todos os boletos que deve, pra não ter chateação. Evite ir ao trabalho, pois situações de pressão emocional só vão dar em merda.

TOURO

Suas convicções são um saco, você tem mais um dia terrível de expressão pessoal pela frente. Evite a autocrítica, você é péssimo nisso. Pouco importa escolher bem suas batalhas, hoje você vai se ferrar em todas elas de qualquer jeito.

AQUÁRIO

Decepção com dificuldades emocionais é o que espera você para hoje. Melhor não praticar o desapego, guarde todos os pesos desnecessários. O contato com familiares pode ser infernal nessa fase, aprenda a colocar cada um deles em seu devido lugar.

\section{CAPRICÓRNIO}

O dia desfavorece estudos e viagens relacionadas ao trabalho. Momento em que você sente haver o pior canal de comunicação com as pessoas. Um dia em que tende a agir de forma mais atabalhoada e ilógica, e isso vai foder com você inevitavelmente.

ÁRIES

Pratique o excesso de crítica e cobrança para observar como isso detona a sua saúde. É um dia pra perceber o que precisa ser mandado às favas. Mantenha o shift+foda-se no automático. O momento é péssimo para seguir a intuição e cultivar vínculos mais profundos.

VIRGEM

Dia tenebroso para se arriscar em projetos ligados a grupos. Pare com essa mania de visão de futuro, e aprimore as idas ao bar para encher a cara, pois até o final da semana tudo vai dar errado pra você. Estudos e viagens são a pior coisa para se investir nessa porcaria de fase.

LIBRA

Dane-se seu guia interior, pois os desafios de hoje demandarão ações ilícitas e sigilosas. Há risco total de conflitos com autoridades e pessoas próximas, prefira mandar todos irem à merda. Para dar conta da depressão, evite acessar e comentar suas bobagens em redes sociais.

SAGITÁRIO

É complicado destrinchar alguns nós com familiares, com seu amor ou sócios, portanto, prefira fingir que não está nem aí pra ninguém. Quando o espiritual, afetivo e material se embolam, o progresso vai dar em bosta lamacenta. Não insista em diálogos, ou você vai quebrar a cara. ${ }^{2}$

\section{Disponível em}

https://www.facebook.com/photo.php?fbid=10209613252955564\&set=a.10202543741782203 $.1073741830 .1455669283 \&$ type $=3$. 
METAgraphias: letra F de \#foulipo (criação potencial) v.2 n.3 setembrol2017 regras para foulipar • Priscila Borges e Gustavo Laet Gomes (primborges@gmail.com; guslaet@gmail.com)

REGRA DA SEMANA DE 2 A 8/7

Escreva numa postagem a premissa de um dito popular com a conclusão de outro. Não se esqueça da \#foulipo.

(Veja um exemplo nos comentários.)

\#fou Foulipo Passarinho que come pimenta tanto bate até que fura. \#foulipo

Tipo Like - Reply - is 1-Commented on by Gustavo Laet Gomes [?] - July 2 at 6:24am

\#fou

Tipo

Write a comment.

(-)

\section{REGRA DAS SEMANAS DE 9 A 23/7}

(1) Escolha uma frase recente de um político contemporâneo, extraída de notícias da imprensa.

(2) Cole-a numa nova postagem do Facebook, entre aspas, e indique, como autor (da frase), algum escritor, poeta, estadista etc., enfim, alguma pessoa das que costumam ter suas frases citadas na internet. De preferência alguém que já morreu. Não se esqueça de acrescentar a \#foulipo.

\section{REGRA DA SEMANA DE 23 A 29/07}

(1) Escolha uma frase significativa na sua timeline (ou seja, uma frase a que você não seja indiferente).

(2) Cole o texto em uma nova postagem e substitua todos os adjetivos por "<adjetivo>" (sem as aspas, mas com os sinais <>). Não se esqueça de acrescentar a \#foulipo.

\section{REGRA DA SEMANA DE 30/7 A 5/8}

Compartilhe um verso de música ou frase (de entrevista, por exemplo) do Caetano Veloso (entre aspas) e indique que o autor é Gilberto Gil. Ou vice-versa. Não se esqueça da \#foulipo. 
METAgraphias: letra F de \#foulipo (criação potencial) v.2 n.3 setembrol2017 regras para foulipar •Priscila Borges e Gustavo Laet Gomes (primborges@gmail.com; guslaet@gmail.com)

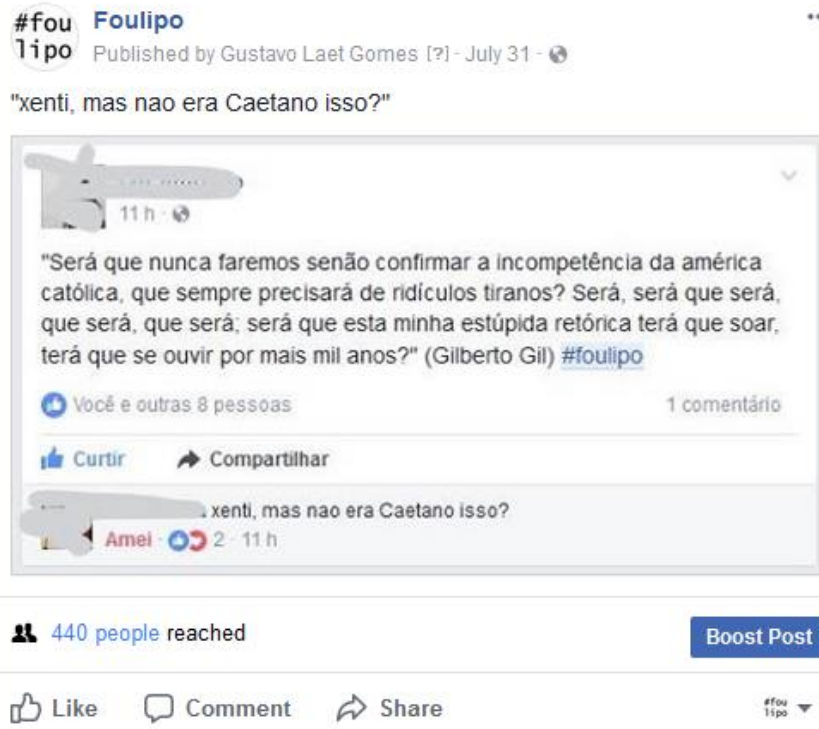

24 440 people reached

D Like $\square$ Comment $\Rightarrow$ Share

$i_{i=\infty}^{+\infty}$

\section{REGRA DA SEMANA DE 6 A $12 / 8$}

Escolha uma notícia de política e compartilhe na sua timeline colocando como texto a chamada de uma notícia de leilão de gado. Não se esqueça de acrescentar a \#foulipo.

(Exemplos de sites de notícia sobre leilões de gado nos comentários.)

\section{REGRA DA SEMANA DE 13 A 19/8}

---- ESPECIAL DIA DOS PAIS ----

(1) Escolha uma foto de um político homem de qualquer época ou lugar.

(2) Escolha um verso de uma música romântica, cujo autor seja um homem, e compartilhe junto com a foto escolhida no passo 1. Não se esqueça de acrescentar a \#foulipo. 
METAgraphias: letra F de \#foulipo (criação potencial) v.2 n.3 setembrol2017 regras para foulipar • Priscila Borges e Gustavo Laet Gomes (primborges@gmail.com; guslaet@gmail.com)

\#fou Foulipo shared Inácio Amaro's post.
Tipo Published by Gustavo Laet Gomes [?] - August 13 -

"Isso é uma pouca vergonha!"

F. Inácio Amaro

August $13 \cdot 0$

"Nós somos dois sem-vergonhas em matéria de amar. Você porque vai e volta, eu por te deixar ficar." \#foulipo

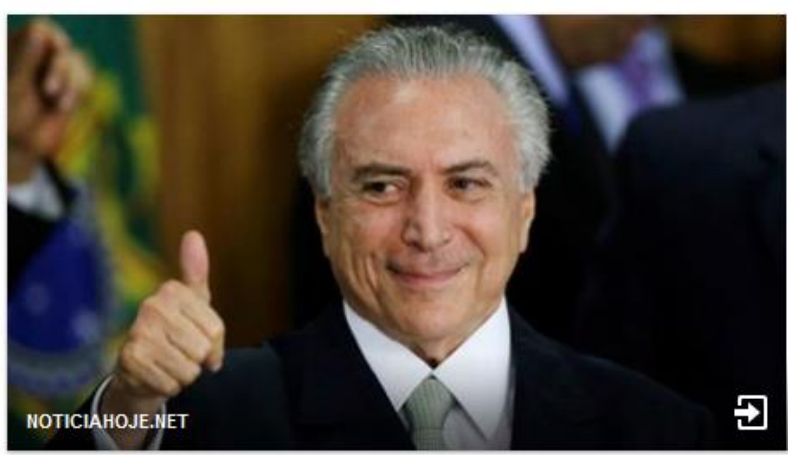

21 103 people reached

D Like $\square$ Comment $\Rightarrow$ Share $\operatorname{tin}_{i \infty \infty} \rightarrow$

\#fou Foulipo shared your post.

1ipo Published by Gustavo Laet Gomes [?] - August 17 - 8

agora todo mundo na dancinha da vassoura

Priscila Borges

August 17 - Brasilia, DF - 0 -

diga aonde você vai, que eu vou varrendo

\#foulipo

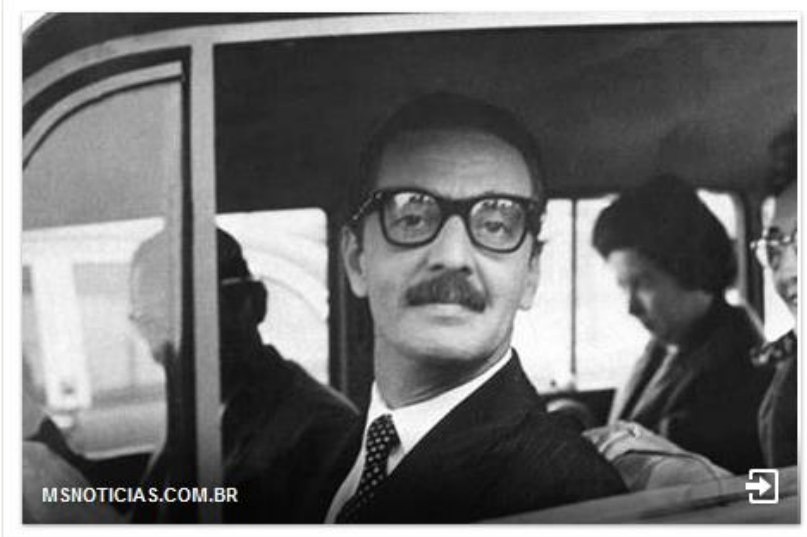

21 109 people reached

0 Like $D$ Comment $\Rightarrow$ Share

$\mathbb{i t w}_{\infty}^{\infty}+$ 
METAgraphias: letra F de \#foulipo (criação potencial) v.2 n.3 setembrol2017 regras para foulipar • Priscila Borges e Gustavo Laet Gomes (primborges@gmail.com; guslaet@gmail.com)

REGRA DA SEMANA DE 20 A 27/8

(1) Entre na sua seção de Amigos (clique no seu perfil e em seguida na opção "Amigos").

(2) Clique em "Novas Publicações".

(3) Procure pelo $2^{\circ}$ amigo ou amiga que tenha um número de "novas publicações" correspondente ao dia da semana: domingo $=1$, segunda $=2$ e assim por diante.

(4) Entre no perfil dela ou dele e escreva o seguinte: "[Fulano], te <verbo>. Você é muito <adjetivo>.", sem as aspas e substituindo apenas [Fulano] pelo primeiro nome da pessoa. Não se esqueça de acrescentar a \#foulipo.

(Se o passo 3 cair em um amigo que você já tenha <elogiado>, pegue o próximo que tiver o número de postagens do dia.)

Nesta regra os participantes devem "cutucar" seus "amigos" escrevendo diretamente em suas timelines. Há um problema, porém, que é o fato de que a maior parte destas postagens não fica pública.

\section{REGRA DA SEMANA DE 27/8 A 2/9}

Nesta semana, a página Foulipo irá criar um evento por dia a partir dos compromissos da agenda da Presidência da República. A regra envolve confirmar participação nos eventos, compartilhá-los e convidar amigos.

(1) Entre na seção 'Eventos' da página Foulipo e clique um evento que ainda não ocorreu. (Caso o evento tenha aparecido na sua timeline, basta clicar nele; não precisa entrar na página).

(2) Confirme presença no evento.

(3) Convide 5 amigos, alternando as letras do alfabeto (tente lembrar a última letra que você usou).

(4) Compartilhe o evento na sua timeline com um texto de sua autoria ou então copiando e colando a descrição do evento. Acrescente no final a \#foulipo.

[Opcional] Entre nos eventos várias vezes por dia e convide mais amigos. 
METAgraphias: letra F de \#foulipo (criação potencial) v.2 n.3 setembrol2017 regras para foulipar • Priscila Borges e Gustavo Laet Gomes (primborges@gmail.com; guslaet@gmail.com)

Esta foi uma primeira tentativa de trabalhar com eventos. Houve um problema, porém, que é o fato de a agenda do presidente não apresentar todos os eventos oficiais e, por vezes, ser atualizada muito em cima da hora. Ainda calhou de ser uma semana em que ele estava na China e a diferença de fuso horário provavelmente atrapalhou a atualização da agenda.

\#fou Foulipo shared their event.

Tipo Published by Gustavo Laet Gomes [?] - August 30 -

Neste encontro, o presidente Miguel Temer sairá direto de seu caixão para vender a Eletrobrás em meia hora para o Sr. Chen Feng, da HNA, multinacional chinesa ultramegablaster, daquelas que exportam até os trabalhadores. \#foulipo
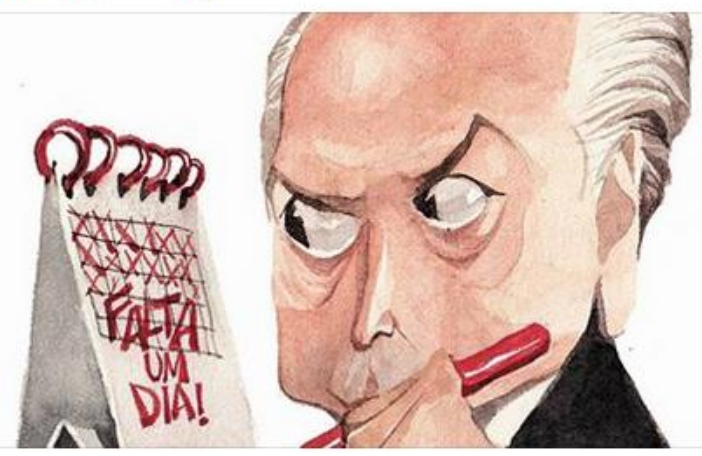

AUG Encontro com o senhor Chen Feng, Pr...

31 Thu 12 PM UTC+08 - Beijing, China Gustavo, Clarissa and 2 friends went

23 35 people reached $\checkmark$ Going $\vee$ Comment $\cdots$

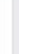

\#fou Foulipo added an event.
Tipo August 29 -
Seguimos acompanhando nosso nosferato. "Vamos conversar dez minutos
com esse camarada que conta uns gracejos espirituosos aos pés de
nossos ouvidos", teria dito Michel Miguel ao aceitar a oferta [estritamente
protocolar] do presidente português.

\#fou Foulipo added an event.
Tipo August 29 -
Seguimos acompanhando nosso nosferato. "Vamos conversar dez minutos
com esse camarada que conta uns gracejos espirituosos aos pés de
nossos ouvidos", teria dito Michel Miguel ao aceitar a oferta [estritamente
protocolar] do presidente português.

\#fou Foulipo added an event.
1ipo August 29 -
Seguimos acompanhando nosso nosferato. "Vamos conversar dez minutos
com esse camarada que conta uns gracejos espirituosos aos pés de
nossos ouvidos", teria dito Michel Miguel ao aceitar a oferta [estritamente
protocolar] do presidente português.

\#fou Foulipo added an event.
Tipo August 29 -
Seguimos acompanhando nosso nosferato. "Vamos conversar dez minutos
com esse camarada que conta uns gracejos espirituosos aos pés de
nossos ouvidos", teria dito Michel Miguel ao aceitar a oferta [estritamente
protocolar] do presidente português.

\#fou Foulipo added an event.
Tipo August 29 -
Seguimos acompanhando nosso nosferato. "Vamos conversar dez minutos
com esse camarada que conta uns gracejos espirituosos aos pés de
nossos ouvidos", teria dito Michel Miguel ao aceitar a oferta [estritamente
protocolar] do presidente português.

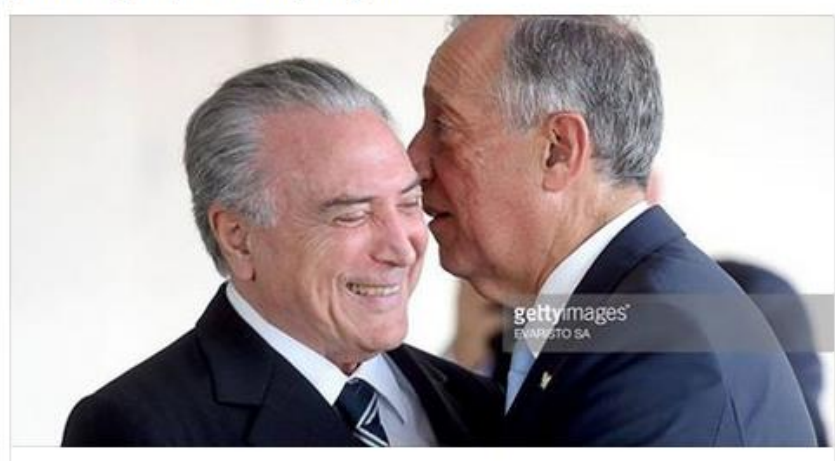

AUG Encontro com Presidente da República...

30 Wed 11:30 AM UTC+01. Aeroporto de Lisboa-Por... $\checkmark$ Going $~$

(6) Boost Unavailable

\section{Gustavo, Clarissa and Ruan went}

(6) Boost Unavailable

Q Comment 
METAgraphias: letra F de \#foulipo (criação potencial) v.2 n.3 setembrol2017 regras para foulipar • Priscila Borges e Gustavo Laet Gomes (primborges@gmail.com; guslaet@gmail.com)

\#fou Foulipo added an event

Tipo August 28 - a

Primeira escala do nosso vampiro favorito em sua viagem com destino à China, onde pretende vender o Estado brasileiro a preço de rolinho primavera.

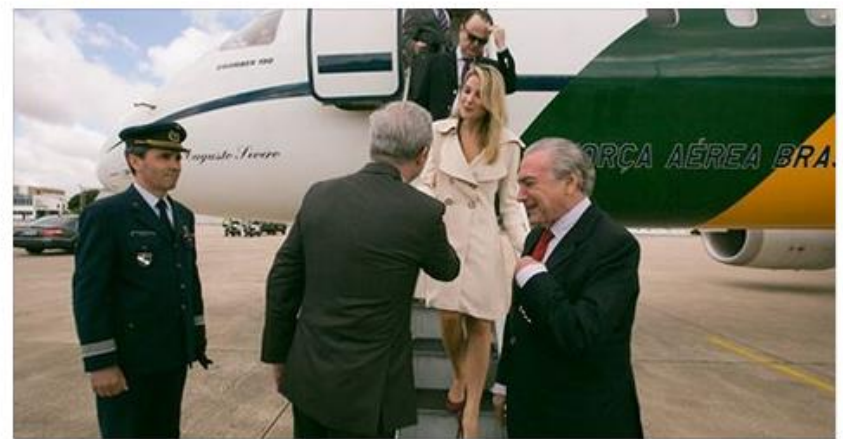

AUG Chegada a Lisboa/Portugal (horário loc...

29 Tue 10:40 PM UTC+01- Aeroporto de Lisboa - Lis... $\checkmark$ Going $~$ Gustavo, Virginia and 3 friends went

(i) Boost Unavailable

D Like $\square$ Comment

$\mathbb{f i s}_{\infty} \times$

\section{\# fou Foulipo added an event.}

Tipo August $28 \cdot \theta$

Nesta reunião, nosso querido Presidente [da Transilvânia, isto é,] do Brasil, irá se reunir com seus [acólitos, isto é,] ministros para discutir os rumos da [vampirização e destruição completa da] nossa economia [, sociedade, natureza, auto-estima, cultura etc.].

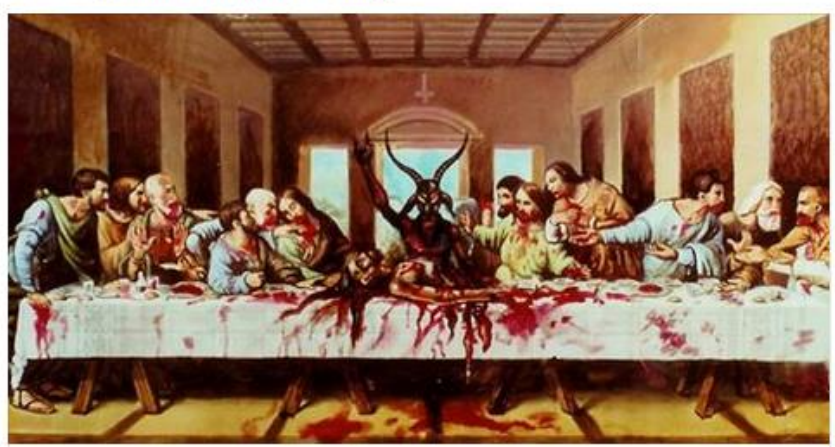

AUG Reunião Ministerial

28 Mon 3:30 PM - Palacio Do Planalto-Brasília, DF $\checkmark$ Going $~$ Clarissa, Gustavo and 10 friends

\#fou Foulipo added an event

1ipo August $27 \cdot$ a

O [vice-]presidente Michel Miguel Temer Lulia, em linha com o lema "não pense em crise, trabalhe", fará o lançamento deste programa de voluntáriado que pretende reduzir o desemprego: "num pais com 14 milhões de desempregados, tem muita gente à toa para ser voluntário".

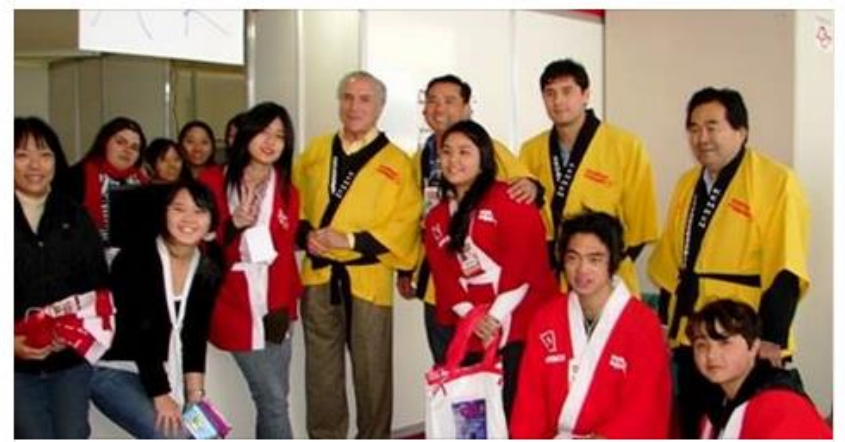

AUG Cerimônia de Lançamento do Program...

28 Mon 11 AM - Palacio Do Planalto-Brasilia, DF $\quad \checkmark$ Going $\checkmark$ Gustavo, Clarissa and 5 friends went

(1) Like Comment 
METAgraphias: letra F de \#foulipo (criação potencial) v.2 n.3 setembrol2017 regras para foulipar • Priscila Borges e Gustavo Laet Gomes (primborges@gmail.com; guslaet@gmail.com)

REGRA DA SEMANA DE 3 A $9 / 9$

Compartilhar a primeira foto ou vídeo de comida que aparecer na sua timeline e colocar, como texto, uma receita de outro tipo de comida.

DICA: Coloque a \#foulipo ao lado do título da receita, e não no final.

Comida é um tema que gera muia repercussão no Facebook.

\section{REGRA DA SEMANA DE 10 A 16/9}

Escolha um texto duro de crítica social ou existencial (ou seja, que critique comportamentos individuais ou sociais).

A regra é que você compartilhe uma frase deste texto por publicação, em sequência, durante toda a semana. Ao final de cada publicação, acrescente a \#foulipo.

(Lembrando que você pode publicar várias vezes por dia.)

Se o seu dispositivo permitir, acrescente um fundo bem feliz à sua publicação. Se o fizer, use sempre o mesmo enquanto durar o texto.

Não use aspas, nem dê a referência do texto. (Mas se alguém perguntar alguma coisa, você pode fornecer a referência nos comentários.)

Esta regra também introduz elementos de fora do Facebook e ainda flerta com a ideia de cópia (ou plágio).

\section{REGRA DA SEMANA DE 17 A 23/9}

1) Escolha uma foto qualquer de um lugar aberto. Pode ser uma foto sua, do Google Imagens ou qualquer outra origem, inclusive do próprio Facebook.

2) Compartilhe apenas com a \#foulipo, marcando, porém, um local (faça check-in). Pode ser qualquer lugar, cidade, país, desde que NÃO SEJA o lugar correspondente à foto.

É provável que algumas pessoas pensem que você está viajando para esse tal lugar. Se fizerem perguntas neste sentido, dê respostas ambíguas, que nem confirmam nem negam que você realmente esteja viajando. 
METAgraphias: letra F de \#foulipo (criação potencial) v.2 n.3 setembrol2017 regras para foulipar • Priscila Borges e Gustavo Laet Gomes (primborges@gmail.com; guslaet@gmail.com)

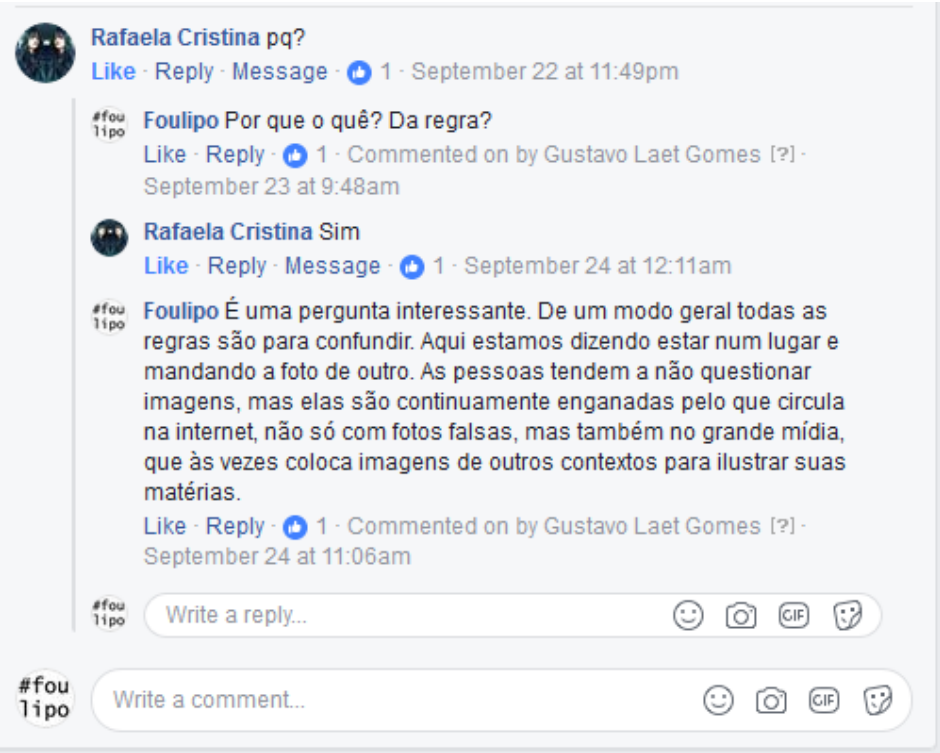

\section{REGRA DA SEMANA DE 24 A 30/9}

1) Entre na sua página de Eventos (fica na lista de links do lado esquerdo da página principal do Facebook).

2) Clique em 'Anteriores' para mostrar eventos que já ocorreram.

3) Clique em um evento do passado em que você não tenha confirmado presença.

4) Confirme presença nesse evento (sim, é possível!).

5) Compartilhe o evento na sua timeline (copie o link na barra de endereços), acrescentando a \#foulipo.

Confirmando presença e instando usuários desavisados a se engajarem em eventos que já ocorreram. (Regra sugerida por Renata Estrella.)

\section{REGRA DA SEMANA DE 1 A 7/10}

Esta regra envolve fazer duas postagens contraditórias em sequência.

$1^{\text {a }}$ Postagem) Escreva uma frase curta expressando uma opinião de forma lapidar e acrescente a \#foulipo. Por exemplo: "Odeio coentro. \#foulipo" (sem as aspas, evidentemente). Escolha, se possível, um dos fundos especiais do Facebook para chamar mais a atenção. 
METAgraphias: letra F de \#foulipo (criação potencial) v.2 n.3 setembrol2017 regras para foulipar • Priscila Borges e Gustavo Laet Gomes (primborges@gmail.com; guslaet@gmail.com)

$2^{\text {a }}$ Postagem) Escreva uma segunda frase, igualmente curta, que seja o oposto da primeira. Por exemplo "Adoro coentro. \#foulipo". Adicione um fundo diferente, se possível um que seja mais ou menos oposto ao da primeira postagem.

É evidente que as opiniões postadas não precisam ser suas (até porque elas são contraditórias e isso seria muito estranho).

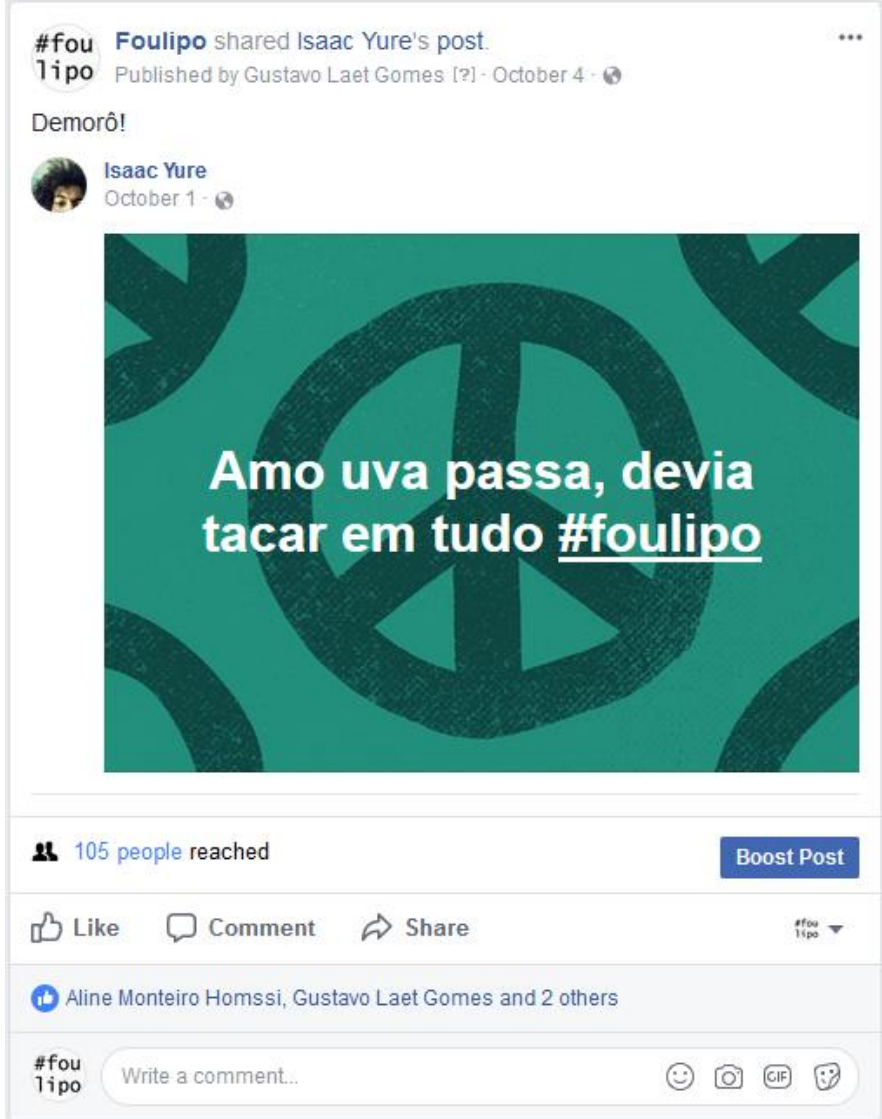

\section{REGRA DA SEMANA DE 8 A 14/10}

1) Escolha uma foto bem garbosa do Michel Temer.

2) Escolha uma fala grandiosa de algum personagem real ou fictício tido como bom orador (tipo um Winton Churchill, Julio César, Policarpo Quaresma, Isócrates).

3) Compartilhe a imagem do passo $1 \mathrm{com}$ a frase do passo 2 entre aspas, mas sem declarar o autor da frase original. A ideia é que pareça que frase foi dita pelo próprio Temer. Não se esqueça da \#foulipo. 
METAgraphias: letra F de \#foulipo (criação potencial) v.2 n.3 setembrol2017 regras para foulipar • Priscila Borges e Gustavo Laet Gomes (primborges@gmail.com; guslaet@gmail.com)

REGRA DA SEMANA DE 15 A 21/10

1) Escolha uma foto dentre as que você tem disponíveis no seu dispositivo. Pode ser uma foto que você tirou com ou sem você ou tirada por outras, mas tem que ser uma foto que você guarde. Não vale buscar fotos no Google.

2) Crie uma narrativa ficcional para a foto e compartilhe-a. Não se esqueça da \#foulipo.

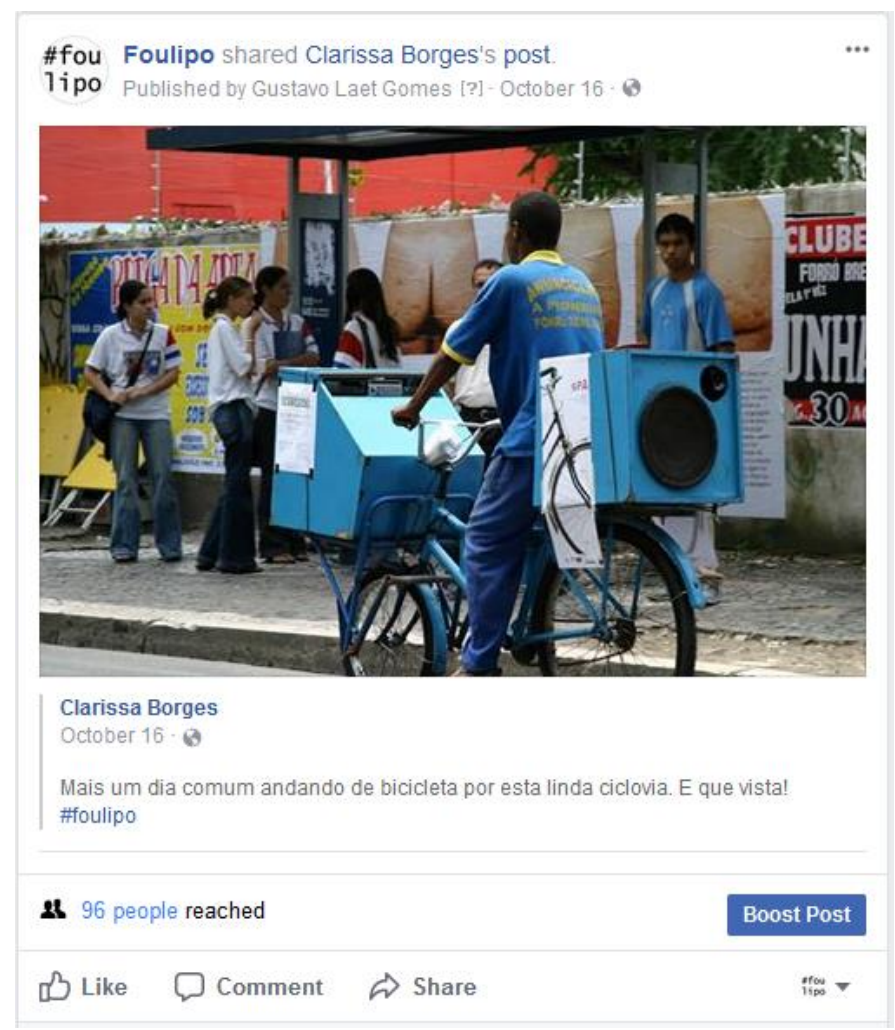


METAgraphias: letra F de \#foulipo (criação potencial) v.2 n.3 setembrol2017 regras para foulipar • Priscila Borges e Gustavo Laet Gomes (primborges@gmail.com; guslaet@gmail.com)

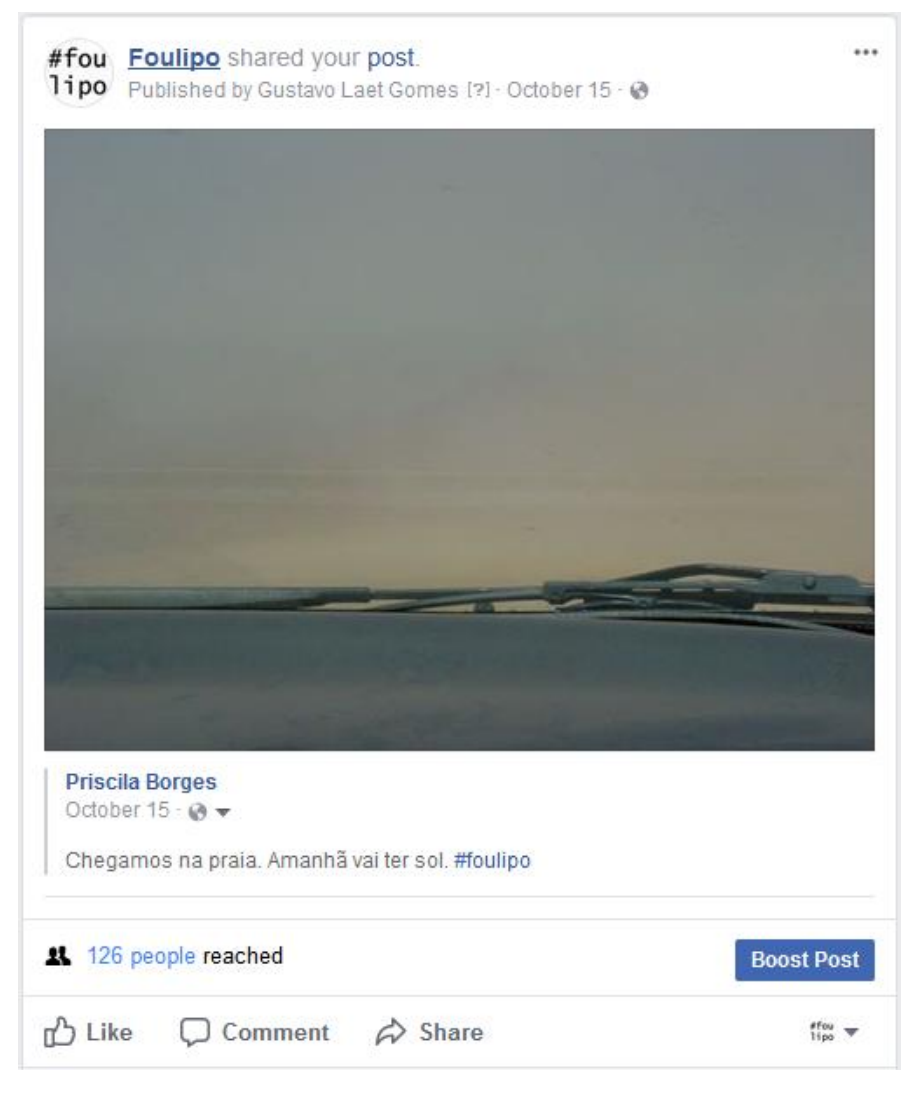

REGRA DA SEMANA DE 22 A 28/10

0) [Opcional] Altere o seu feed de notícias para mostrar as histórias mais recentes.

1) Copie o texto da $5^{a}$ publicação que aparecer no seu feed.

2) Compartilhe esse texto com a primeira notícia que aparecer no seu feed depois da $5^{\text {a }}$ publicação, acrescentando a \#foulipo.

\section{REGRA DA SEMANA DE 29/10 A 4/11}

Publique um verbo no infinitivo seguido da \#foulipo.

[Opcional: relacione sequências de verbos (da forma que você quiser) publicando os verbos de uma mesma sequência com o mesmo pano de fundo.]

\section{REGRA DA SEMANA DE 5 A 11/11}

(1) Escolha uma foto de qualquer origem, de um objeto ou cena aleatória (uma árvore, 
um balde, a pia do banheiro, uma estante, qualquer coisa banal).

(2) Compartilhe com os dizeres "INDIGNAÇÃO! PASSARAM DOS LIMITES!" (ou equivalente), acrescentando a \#foulipo.

(Regra sugerida por Inácio Amaro.)

\section{REGRA DA SEMANA DE 12 A 18/11}

Escolha uma foto de um objeto qualquer e compartilhe dizendo "Vendo" mais o nome do objeto. Não se esqueça de acrescentar a \#foulipo.

\section{REGRA DA SEMANA DE 19 A 25/11}

(1) Escolha um trecho de uma música de algum artista americano adolescente (não importa o gênero, de até 20 anos).

(2) Traduza o trecho escolhido (pode usar tradudores automáticos ou fazer uma tradução autoral).

(3) Publique como se fosse de algum cantor da MPB (até os anos 1980) com a \#foulipo.

Foi difícil encontrar artistas americanos de até 20 anos. Foi preciso disponibilizar uma lista para os participantes.

\section{REGRA DA SEMANA DE 26/11 A 2/12}

(1) Entre na sua seção de Amigos (clique no seu perfil e em seguida na opção "Amigos").

(2) Clique em "Novas Publicações".

(3) Procure pelo $2^{\circ}$ amigo ou amiga que tenha um número de "novas publicações" correspondente ao dia da semana: domingo $=1$, segunda $=2$ e assim por diante.

(4) Entre no perfil dela ou dele e escreva o seguinte: "[Fulano], parabéns! \#foulipo.", sem as aspas e substituindo apenas [Fulano] pelo primeiro nome da pessoa.

[Opcional: Adicione um fundo festivo à sua postagem.] 
METAgraphias: letra F de \#foulipo (criação potencial) v.2 n.3 setembrol2017 regras para foulipar • Priscila Borges e Gustavo Laet Gomes (primborges@gmail.com; guslaet@gmail.com)

(Se o passo 3 cair em um amigo que você já tenha parabenizado, pegue o próximo que tiver o número de postagens do dia.)

\section{Conclusão}

Regras que permitiam o compartilhamento de conteúdos gráficos tinham maior impacto quando comparadas com regras que trabalhavam apenas com texto. Dentre as regras de conteúdo gráfico, eram ainda mais expressivas aquelas que continham vídeos ou fotos que os leitores poderiam pensar que fosse dos próprios publicadores.

No início, houve um estranhamento com o conteúdo bizarro das postagens e com a \#foulipo. Pouco a pouco, porém, os seguidores dos participantes foram se acostumando com a presença da \#foulipo e passaram a não estranhar mais as bizarrices. Em alguns círculos, certos usuários passaram a considerar \#foulipo como uma espécie de indicativo de fake news ou conteúdo falso em geral, o que consideramos um resultado positivo.

Na página www.facebook.com/foulipo é possível encontrar exemplos em que a aplicação das regras gerou resultados particularmente interessantes. Não pudemos, porém, fazer uma avaliação extensiva, nem muito menos quantitativa do impacto do movimento porque o Facebook não libera para todos os usuários uma pesquisa completa por hashtag, ainda que ele tenha ferramentas para isso. $\mathrm{O}$ acesso a este tipo de ferramenta é restrito a grandes grupos de mídia que têm contratos especiais com o Facebook, o que não é o nosso caso.

Gostaríamos ainda de agradecer a todos os participantes, especialmente aqueles que contribuíram votando ou sugerindo regras. 